\title{
Children's Preference for Real Activities: Even Stronger in the Montessori Children's House
}

\author{
Jessica Taggart, Eren Fukuda, and Angeline S. Lillard \\ University of Virginia \\ Keywords: children, Montessori, preschool, activities, preferences, pretend, real
}

\begin{abstract}
In the United States, children are often given the opportunity to engage in pretend activities; many believe this kind of play benefits children's development (Haight \& Miller, 1993; Haight, Masiello, Dickson, Huckeby, \& Black, 1994; Parmar, Harkness, \& Super, 2004; Roopnarine, 2010). Recent research has shown, though, that when children ages 4 to 6 are given a choice to do the pretend or the real version of 9 different activities, they would prefer the real one (Taggart, Heise, \& Lillard, 2018). The reasons children gave for preferring real activities often concerned their appreciation of the functionality; when children did prefer pretend activities, their reasons often cited being afraid of, not allowed to, or unable to do the real activity. Given that children in Montessori classrooms have more experience performing real, functional activities, in this study we asked if this preference for real activities is even stronger among children in Montessori schools. We also asked children to explain their preferences. The data are from 116 3- to 6-yearold children $(M=59.63$ months, $S D=12.08$ months; 68 female): 62 not in Montessori schools and 54 in Montessori schools. Children explained their preferences for pretend and real versions of 9 different activities. Children in Montessori schools preferred real activities even more than did children in other preschools, but all children explained their choices in similar ways. The implications of these results are discussed with regard to play in preschool classrooms.
\end{abstract}

Play is a highly valued activity in the United States; many parents, as well as the American Academy of Pediatrics, believe it is important, and even essential, for children's development (Ginsburg, 2007; Haight \& Miller, 1993; Haight et al., 1994; Parmar et al., 2004; Roopnarine, 2010). Americans spent more than \$20.7 billion on toys in 2017 (NPD Group, 2018), and a popular toy category is materials for pretending (e.g., plastic foods, dolls, dress-up clothes). Furthermore, American children spend nearly $20 \%$ of their waking hours engaged in pretend play (Dunn \& Dale, 1984; Haight \& Miller, 1993): having tea parties with dolls, building forts, or making pretend meals in play kitchens. Conventional American preschools often have play-based curricula (e.g., HighScope; Schweinhart et al., 2005) and provide materials to facilitate playing "house" in the classroom, for example (Parmar et al., 2004; Rubin, 1977). Like parents (Singer, Singer, DiAgostino, \& DeLong, 2009), preschool teachers highly value play and believe it facilitates children's learning (Bodrova, 2008; Engel, 2015; Sandberg \& Samuelsson, 2003; Sherwood \& Reifel, 2010). 
In line with these views, educational organizations such as the National Association for the Education of Young Children (NAEYC) and the Association for Childhood Education International advise educators to provide environments and materials that facilitate play (Copple \& Bredekamp, 2009; Isenberg \& Quisenberry, 2002); second on the NAEYC's (2018, Toys for 3- to 6-year-olds) list of best toys for 3- to 6-yearolds is "things for pretending."

Proponents of play criticize classrooms and teachers for shifting away from play-based curricula, claiming that a reduction in children's play may lead to negative outcomes (Kemple, Oh, \& Porter, 2015). There is concern that kindergarten is becoming the new first grade, with incessant focus on academics and few opportunities for play (Bassok, Latham, \& Rorem, 2016). In response, developmental psychologists have called on educators to bring play back to the classroom (Hirsh-Pasek, Golinkoff, Berk, \& Singer, 2009). This concern and subsequent efforts to reinstate play arose because, in conventional schools, shifting away from play meant shifting toward regimented, teacher-led classroom environments. Montessori education offers a different choice.

Montessori education is in many ways playful, but it does not offer typical pretend-play materials. Initially it did, but children did not use them. As Maria Montessori described it,

Although the children in our first school could play with some really splendid toys, none cared to do
so. This surprised me so much that I decided to help them play with their toys, showing them how
to handle the tiny dishes, lighting the fire in the doll's kitchen, and placing near it a pretty doll. The
children were momentarily interested but then went off on their own. Since they never freely chose
these toys, I realized that in the life of a child play is perhaps something of little importance which
he undertakes for the lack of something better to do. A child feels that he has something of greater
[importance] to do than to be engaged in such trivial occupations. He regards play as we would
regard a game of chess or bridge. These are pleasant occupations for hours of leisure, but they
would become painful if we were obliged to pursue them at great length. (Montessori, 1966, p. 122)

Because Dr. Montessori noted that children loved using miniature objects to engage in real activitiesactivities they see performed by the adults in their culture-Montessori classrooms provide many of these, calling them Practical Life activities. After engaging in such activities, "the child showed a completely different personality. The first result was an act of independence, as if he said: 'I want to be self-sufficient" (Montessori, 1949, p. 245). Montessori classrooms provide children opportunities to prepare real food with real knives; to use and wash real, breakable dishes; and so on. Pretend play is sometimes even discouraged (Soundy, 2009), particularly if it involves using materials as toys rather than as learning tools (e.g., using Pink Tower blocks to build houses and create imaginary characters instead of building a concentric tower), but Montessori teacher trainers note that one should never stop a child from pretending. Instead, one should meet children where they are and use whatever interests them to connect them to the fascination of the real world, where useful creativity and imagination are best rooted (L. Lawrence, personal communication, October 4, 2017; G. Sackett, personal communication, May 30, 2018).

Dr. Montessori's observations suggest that, given a choice, children prefer real activities to their pretend counterparts. Taggart et al. (2018) recently conducted a study to examine if this is the case. Children ages 3 to 6 were shown pictures of boys and girls engaged in pretend and real versions of nine different activities (e.g., riding a tractor, cutting vegetables, feeding a baby). They were asked which activity they would rather participate in and why. Children strongly preferred real activities, often alluding to functionality in their justifications: they could really go fast when riding a real horse, or they could really enjoy a yummy treat when baking real cookies. In contrast, when asked why they preferred the pretend activities, children often expressed being unable, unwilling, or unallowed to do the real thing; they could get a hook stuck in their finger when really fishing, or their parent would not allow them to use real knives yet. The children in this study were enrolled in various types of preschools, but preschool type was not considered 
a variable of interest because most children were enrolled in non-Montessori schools, precluding comparisons across school types.

We wanted to know if being at a school in which one engages in real activities and has fewer schoolday opportunities to engage in pretend ones influences children's preferences. We therefore tested a group of children attending Montessori schools. According to children's justifications in Taggart et al. (2018), it is possible that children in Montessori schools may feel less afraid of, more competent at, and more permitted to do real things and, therefore, may choose real activities more frequently. On the other hand, given that children in Montessori schools lack opportunities to pretend at school, they might have an unfulfilled desire to pretend that would lead them to choose pretend activities more often. We also examined whether, relative to the type of school, children's preferences for pretend over real activities change with age (from 3 to 6 years old) or vary by gender. Both of these scenarios were observed by Taggart et al. (2018): 3-year-olds were equally divided in their preference for real activities, and boys showed an even stronger reality preference than girls (although girls preferred real activities as well). Data from a subsample of this study were previously reported in Taggart et al. (2018); the Montessori sample was increased here to allow reliable subgroup comparisons.

\section{Method}

\section{Participants}

Participants included 116 children: 100 participated in the study reported by Taggart et al. (2018), including 62 children enrolled in non-Montessori preschools $(M=59.43$ months old, $S D=12.22$ months, range $=37.2-82.3$ months; 57\% female): 13 three-year-olds, 19 four-year-olds, 20 five-year-olds, and 10 six-year-olds. Twenty-nine of these children attended private preschools, 10 attended public preschools, three were homeschooled, two attended Waldorf schools, one attended Head Start, seven were in schools that could not be identified (e.g., "preschool in North Carolina"), and 10 were not currently in school. Fifty-four children, including 16 participating exclusively in this study, were enrolled in Montessori schools $(M=59.85$ months old, $S D=12.03$ months, range $=36.8-81.2$ months; $61 \%$ female $): 12$ three-year-olds, 12 four-year-olds, 20 five-year-olds, and 10 six-year-olds. The children enrolled in Montessori schools represented at least seven different schools, which were identified by parent reporting of the type or name of their child's school or by testing location (i.e., a Montessori school). Of the five schools identified by name, one was accredited by the Association Montessori International (AMI, n.d.), and two were accredited by the American Montessori Society (AMS, n.d.) The remaining two schools were not listed on the AMI or AMS websites, but the school websites showed that at least some of their teachers were AMI or AMS trained. Children in both non-Montessori preschools and Montessori schools were predominantly White and middle class. Four additional children participated but were excluded from analyses because of failure to complete $(n=3)$ or understand $(n=1)$ the task.

\section{Materials and Procedure}

Participants were tested in a children's museum $(n=50)$, local Montessori preschools $(n=43$, including all 16 children participating exclusively in this study), and a university laboratory $(n=23)$. Participants' parents provided written consent, and all children verbally agreed to participate. In addition, for the testing that took place in schools, the head teachers consented to have the study take place in a quiet corner of the classroom.

Participants were seated across from the experimenter as she explained the study: "I have a book with all kinds of different activities that you could do. I'm going to ask you which ones you would rather do. Does that sound good?" After the participant assented, the experimenter presented a book $(22$ x $28 \mathrm{~cm})$ containing color photographs of girls or boys (gender matched to the participant) engaged alone in different activities. The children in the photographs were of various races and were not matched to the child's own 
race. The experimenter first presented the warm-up trial, in which a photograph of a child riding a bicycle was on the left side of the page and a photograph of a child with a skinned knee was on the right side of the page: "Look, this girl is riding a bicycle [pointing to the appropriate photograph], and this girl fell off of a bicycle and hurt her knee [pointing to the appropriate photograph]. Which would you rather do?" Participants were then asked to justify their choice.

Nine test trials immediately followed. The order for these nine test trials was randomly determined and then kept constant for all participants. As in the warm-up, the experimenter showed the participant a pair of photographs: in one photograph, a child was engaged alone in a pretend activity, and in the other photograph, a child was engaged alone in a real activity. Each photograph was described to the participant as the experimenter pointed to it: "Look, this girl is pretending to wash dishes, and this girl is really washing dishes. See? These are pretend dishes, and these are real dishes." Whether the pretend activity was on the left or the right alternated by trial, and the experimenter always referred to the photograph on the left (from the participant's perspective) first. Participants were asked for their preference: "Which would you rather do?" After making their choice, they were asked to justify that choice: "Why would you rather [participant's choice]?" The nine activities included eating ice cream, riding a horse, baking cookies, feeding a baby, cutting vegetables, talking on a telephone, riding a tractor, fishing, and washing dishes.

Coding. Participants' justifications for their pretend and real choices were coded into the five discrete categories used by Taggart et al. (2018). The first category was ability, which included references to the child's ability to carry out the activity, avoiding a negative outcome associated with the activity, or whether they are allowed to engage in the activity (e.g., "I am not old enough to do it," "I don't want to get hurt," "My mom doesn't let me.") The second was experience, which included references to participants' experience with the particular activity (e.g., "I've done it before," "I've never done it before."). The third category was functionality, which included references to the affordances of real and pretend activities, as well as the usefulness of the activity (e.g., "I could eat it," "It really moves."). The fourth category was liking, which included references to enjoyment of activity (e.g., "It's fun," "I like it."). Other responses (19\% of the total) did not fit within these categories and so were categorized as uncodable (e.g., "I don't know."). Participants received only one justification code for each trial; if they provided more than one justification, their first justification was used unless the first justification fell in the liking category, in which case their second justification was used. This practice allowed richer, more meaningful justifications than simple liking. Cohen's kappa was run on $20 \%$ of children's justifications to determine interrater agreement for this categorical scale. Agreement was high: $\kappa=.87(95 \% \mathrm{CI}: .82-.93), p<.001$.

\section{Results}

We first considered children's choices by subgroup and then examined their explanations for their choices. An ANOVA with school (i.e., non-Montessori, Montessori), age group (i.e., 3, 4, 5, 6), and gender (i.e., male, female) as between-subject variables and number of pretend choices as the dependent variable revealed main effects for type of school, age group, and gender, but no interactions. The main effects for gender and age group were consistent with Taggart et al. (2018) and are not discussed further here, since the focus of the study was on whether responses would vary by type of school.

The number of times children chose pretend activities differed by type of school, $F(1,100)=5.08, p=$ $.026, \mathrm{~h}_{p}{ }^{2}=.05$ (a small-medium effect size). Children in Montessori schools $(M=2.76, S D=2.46)$ chose pretend activities less often than children in non-Montessori schools $(M=3.50, S D=2.65)$. Fisher's exact tests indicated that this difference was particularly strong for two activities: Montessori children especially preferred really cutting vegetables ( $p=.004$, Cramer's $\mathrm{V}=.28$, a small-medium effect size) and fishing ( $p$ $=.03$, Cramer's $\mathrm{V}=.21$, a small-medium effect size) compared to children not in Montessori schools.

Age was significantly related to pretend choices in non-Montessori schools, $r(60)=-.36, p=.004$, but not in Montessori schools, $r(52)=-.20, p=.15$. However, the correlation in Montessori schools was in 
the expected direction, suggesting that, in both school environments, the tendency to prefer real activities strengthens similarly with age. At age 3, about half of children's choices were for pretend activities, and at age 4 children began to strongly prefer real activities.

\section{Justifications}

The percentages of justifications by age group (i.e., 3, 4, 5, 6) and school (i.e., non-Montessori, Montessori) are shown in Tables 1 and 2, respectively. Each percentage of justifications for the four codable categories for real choices and pretend choices was analyzed with a separate MANOVA, using type of school and age group as fixed factors. For both real and pretend choices, there was a significant effect of age group but not of type of school, and there was no interaction.

Table 1

Mean Percentages of Children's Justifications for Choice by Age Group

\begin{tabular}{|c|c|c|c|c|c|c|c|c|}
\hline \multirow[b]{3}{*}{ Categorization } & \multicolumn{4}{|c|}{ Pretend justifications } & \multicolumn{4}{|c|}{ Real justifications } \\
\hline & \multicolumn{4}{|c|}{ Age group } & \multicolumn{4}{|c|}{ Age group } \\
\hline & 3 & 4 & 5 & 6 & 3 & 4 & 5 & 6 \\
\hline Ability & 4 & 39 & 50 & 64 & 0 & 4 & 5 & 3 \\
\hline Experience & 11 & 12 & 7 & 14 & 8 & 12 & 11 & 19 \\
\hline Functionality & 7 & 4 & 7 & 9 & 10 & 32 & 48 & 46 \\
\hline Liking & 29 & 29 & 23 & 4 & 30 & 40 & 29 & 24 \\
\hline Uncodable & 49 & 16 & 13 & 9 & 43 & 12 & 7 & 8 \\
\hline
\end{tabular}

Table 2

Mean Percentages of Children's Justifications for Choice by Schooling

\begin{tabular}{lcccc}
\hline & \multicolumn{2}{c}{ Pretend justifications } & \multicolumn{2}{c}{ Real justifications } \\
\cline { 2 - 5 } Categorization & Non-Montessori & Montessori & Non-Montessori & Montessori \\
\hline Ability & 43 & 32 & 5 & 2 \\
Experience & 13 & 7 & 13 & 11 \\
Functionality & 7 & 6 & 40 & 34 \\
Liking & 17 & 30 & 28 & 35 \\
Uncodable & 20 & 25 & 14 & 18 \\
\hline
\end{tabular}

For real choices, the significant age effect concerned the number of children in each age group who cited reasons related to functionality (e.g., "I can actually catch fish and eat them," "I could talk to my grandparents [on the real phone]"), $F(3,104)=5.67, p=.001, \mathrm{~h}_{p}{ }^{2}=0.14$ (a medium-large effect size). Post hoc tests showed this was because 3-year-olds $(M=0.19, S D=0.31)$ explained their real choices in this way significantly less often than 5-year-olds $(M=0.48, S D=0.27, p<.001)$ and 6 -year-olds $(M=0.46, S D=0.30, p$ $=.004)$; 4-year-olds $(M=0.32, S D=0.29)$ also used this explanation less often than 5-year-olds $(p=.021)$.

For pretend choices, ability was cited more often as children got older, $F(3,89)=12.26, p<.001, \mathrm{~h}_{p}^{2}$ $=0.29$ (a large effect size); for example, a child chose to pretend to eat ice cream "because I don't know 
how to make ice cream," and another chose to pretend to feed a baby doll "because you wouldn't get dirty from baby guck." Here there were significant differences between 3-year-olds $(M=0.04, S D=0.11)$ and 4-year-olds $(M=0.39, S D=0.42, p=.001), 5$-year-olds $(M=0.50, S D=0.35, p<.001)$, and 6-year-olds $(M=0.64, S D=0.41, p<.001)$, and between 4-year-olds and 6-year-olds $(p=.036)$.

Although not significantly different, explanations by school type are interesting to explore. In explaining real choices, children in non-Montessori schools appealed to functionality somewhat more often (40\%) than they appealed to liking (28\%), whereas children in Montessori schools appealed to functionality and liking at similar rates (34\% and 35\%, respectively). For pretend choices, children in non-Montessori schools appealed to ability (e.g., "I don't know how to bake anything," "[Real horses] go really fast and you might fall off," "My mom doesn't let me use knives because I'm not a grown-up yet.") a bit more often (43\%) than children in Montessori schools (32\%). Children in Montessori schools appealed to liking (30\%) more often than did children in non-Montessori schools (17\%). Additionally, children in non-Montessori schools explained their pretend choices with reference to experience slightly more often ( $13 \%$ versus $7 \%)$; for example, one non-Montessori-schooled child said she preferred to pretend because "I have a pretend kitchen."

\section{Discussion}

Preschoolers enrolled in non-Montessori and Montessori schools were asked whether they would rather engage in the pretend or real version of nine different activities that were selected for the study because children could feasibly do the activities in either manner. Compared to peers in non-Montessori preschools, children in Montessori schools chose fewer pretend activities. Hence, while all children ages 4 to 6 preferred real activities to pretend ones, this preference was even stronger for children attending Montessori preschools (with a small-medium effect size). Children's reasons for their activity choices did not vary by school type. Regardless of school type, children preferred real activities most often because those activities were functional (e.g., "I could talk to people [on a real phone]"); this type of explanation increased from age 3 to age 6 . When children preferred pretend activities, regardless of school type, they often cited concerns about their ability to do the real version (e.g., "I might fall into the water [if I really fish]"); this tendency also increased with age. We hypothesized that children enrolled in Montessori preschools may more strongly prefer real activities because they are more accustomed to engaging in real activities, or might prefer pretend activities because for at least 15 hours a week during the school year, they are not offered an array of pretend implements. However, school type did not figure differently in children's explanations of their choices. To some degree, type of school may have surfaced in the choices themselves: Children in Montessori schools preferred cutting vegetables - an activity they likely experienced in their classrooms as they prepared their own snacks - more than children in non-Montessori schools did.

This study sheds light on an important issue in Montessori education relative to other preschool programs. Montessori education has been criticized for its lack of support for pretending (Kirkham \& Kidd, 2017; Soundy, 2009), yet it appears that the children do not relish it; like their peers in non-Montessori preschools, they prefer to engage in real activities over pretend ones. They see the functionality of real activities, comment on their usefulness, and express liking being helpful by doing the real thing. These findings align with Dr. Montessori's observations. Perhaps many educators, in their concern about preschools' greater focus on academics (Bodrova, 2008; Kemple et al., 2015), may promote pretend play at the expense of giving children real and useful activities. Montessori education lacks toys and pretend-play materials but allows children to move around, explore, make choices freely, and work with their peers and with real materials (Lillard, 2013). Thus, Montessori education shows that the opposite of play does not have to be sitting in a chair listening to a teacher, and Montessori education provides a way to consider how real activities may be implemented in classrooms in ways that allow children to feel they are doing something useful.

In this study, children attended at least seven different Montessori schools. The fidelity of Montessori implementation can vary greatly (Lillard, 2012; Lillard \& Heise, 2016), and so it is possible that children in some classrooms were exposed to more opportunities to engage in pretend play than would be expected 
in the classic curriculum. The number of Montessori schools included in our study sample is a strength, suggesting we were more likely to have captured a range of Montessori implementation rather than a single model.

Limitations of this study should also be noted. First, the sample size was relatively small and lacked diversity; most children were White and middle class. Children of different social classes and ethnicities may have different preferences and explanations. Second, the justification portion of the study relied on children's ability to give verbal explanations, so justification patterns need to be interpreted with caution. Younger children often repeated "because I like it" in response to the justification questions, whereas older children were able to come up with more-complex answers, such as "because we have to [cut real vegetables] because it is healthy for you to eat." Verbal and cognitive abilities may explain the age differences more so than actual reasons.

Third, the pretend activities used here represented only one facet of pretend play: activities that are very similar to their real-world equivalents. Therefore, we cannot say whether our findings generalize to other types of pretend play. Children's interest in pretend may be greater when fantastic content is included or when role play, rather than a particular pretend action, is the focus of the activity.

Fourth, in this study, children were not randomly assigned to school groups. Consequently, it is possible that families of children who attend Montessori schools may have different home environments, too. Perhaps Montessori families also allowed children more opportunities to experience real activities at home because children have experience with those activities in the classroom, or they chose Montessori education because they wanted their children to have these experiences. Therefore, we cannot tease out Montessori education as the single causal factor that leads to decreased interest in pretend activities: varying home environments (e.g., access to pretend or real materials, needs of the particular household, level of adult supervision), parents' philosophies (e.g., how much they value children's practical life experiences over playing, how they judge children's abilities, how they view children's roles in society), and children's temperament (e.g., more or less active, shy) likely relate to school choice and affect children's activity preferences as well.

Finally, the present findings raise new questions for future study. For example, what unique role may school type, independent of other factors, play in children's activity preferences? If children value real activities, then why do they engage in pretend play? And does experience with real tasks provide the developmental benefits that Dr. Montessori (1949) has claimed it does? Answers to these questions will suggest whether and how to implement pretend play and real activities into preschool classrooms to best promote children's development.

\section{Conclusion}

Consistent with Dr. Montessori's observations, children preferred real activities to pretend ones, and this preference appeared more pronounced for children enrolled in Montessori schools than for children enrolled in non-Montessori preschools. Although many educators and researchers raise concerns about not including pretend play in preschool classrooms, children in Montessori classrooms expressed a preference for engaging in real activities that was even somewhat stronger than the preference shown by children in other preschool environments, suggesting that their classroom environment was, in fact, well aligned with their preference. When Dr. Montessori saw children ignore or break pretend materials, she said,

The real trouble is that children have no real interest in these things, because there is no reality in them. It is the misunderstanding by the adult that has led to this life of lack of attention on the part of the children; this useless life, a mockery of life instead of real life...the longer [a child] lives in this environment full of toys, the less capable [the child] becomes of adapting himself to the real environment. (Montessori, 1949, pp. 241-242) 
Might it be that, as Dr. Montessori stated, engaging in pretend play at the expense of real activities is useless or possibly even in some cases harmful to children? In learning environments, greater interest is related to greater motivation and engagement, which leads to learning and achievement (Blumenfeld, Kempler, \& Krajcik, 2004). The choice between work and play may seem binary, but Montessori education's philosophy of engaging children in real activities suggests a different perspective: Children gravitate to real, practical activities; by supporting their interest, we may facilitate greater learning in the classroom.

\section{References}

American Montessori Society. (n.d.). AMS member schools. American Montessori Society. Retrieved from https://amshq.org/School-Resources/AMS-Member-Schools

Association Montessori International. (n.d.). School locator. Association Montessori International. Retrieved from https://amiusa.org/school-locator-2/

Bassok, D., Latham, S., \& Rorem, A. (2016). Is kindergarten the new first grade? AERA Open, 1, 1-31. doi:10.1177/2332858415616358

Blumenfeld, P. C., Kempler, T. M., \& Krajcik, J. S. (2004). Motivation and cognitive engagement in learning environments. In R. K. Sawyer (Ed.). The Cambridge handbook of the learning sciences (pp. 475-488). New York, NY: Cambridge University Press.

Bodrova, E. (2008). Make-believe play versus academic skills: A Vygotskian approach to today's dilemma of early childhood education. European Early Childhood Education Research Journal, 16, 357-369. doi:10.1080/13502930802291777

Copple, C., \& Bredekamp, S. (2009). Developmentally appropriate practice in early childhood programs serving children from birth through age 8. Washington, DC: National Association for the Education of Young Children.

Dunn, J., \& Dale, N. (1984). I a daddy: 2-year-olds' collaboration in joint pretend with sibling and with mother. In I. Bretherton (Ed.), Symbolic play: The development of social understanding (pp. 131-158). Orlando, FL: Academic Press. doi:10.1016/B978-0-12-132680-7.50009-0

Engel, M. (2015). The importance of free play in the early childhood classroom: Perspectives from a teacher. Childhood Education, 91, 323-324. doi:10.1080/00094056.2015.1090842

Ginsburg, K. (2007). The importance of play in promoting healthy child development and maintaining strong parent-child bonds. Pediatrics, 119, 182-191. doi:10.1542/peds.2011-2953

Haight, W. L., \& Miller, P. J. (1993). Pretending at home: Early development in a sociocultural context. Albany, NY: SUNY Press.

Haight, W. L., Masiello, T., Dickson, K. L., Huckeby, E., \& Black, J. (1994). The everyday contexts and social functions of spontaneous mother-child pretend play in the home. Merrill-Palmer Quarterly, 40, 509-522. https://www.jstor.org/stable/23087920

Hirsh-Pasek, K., Golinkoff, R., Berk, L., \& Singer, D. (2009). A mandate for playful learning in preschool: Presenting the evidence. New York, NY: Oxford University Press.

Isenberg, J. P., \& Quisenberry, N. (2002). Play: Essential for all children. A position paper of the Association for Childhood Education International. Childhood Education, 79(1), 33-39. doi:10.1080/000940 56.2002 .10522763

Kemple, K. M., Oh, J. H., \& Porter, D. (2015). Playing at school: An inquiry approach to using an experiential play lab in an early childhood teacher education course. Journal of Early Childhood Teacher Education, 36, 250-265. doi:10.1080/10901027.2015.1062830

Kirkham, J. A., \& Kidd, E. (2017). The effect of Steiner, Montessori, and National Curriculum education upon children's pretence and creativity. The Journal of Creative Behavior, 51, 20-34. https://doi. org $/ 10.1002 /$ jocb. 83

Lillard, A. S. (2012). Preschool children's development in classic Montessori, supplemented Montessori, and conventional programs. Journal of School Psychology, 50, 379-401. doi:10.1016/j.jsp.2012.01.001 
Lillard, A. S. (2013). Playful learning and Montessori education. American Journal of Play, 5, 157-186. Retrieved from http://www.journalofplay.org/sites/www.journalofplay.org/files/pdf-articles/5-2-article-play-learning-and-montessori-education 0.pdf

Lillard, A. S., \& Heise, M. J. (2016). Removing supplementary materials from Montessori classrooms changed child outcomes. Journal of Montessori Research, 2(1), 16-26. doi:10.17161/jomr.v2i1.5678

Montessori, M. (1949). The absorbent mind. Adyar, India: The Theosophical Publishing House.

Montessori, M. (1966). The secret of childhood (M. J. Costello, Trans.). New York, NY: Ballantine.

National Association for the Education of Young Children. (2018). Good toys for young children by age and stage. Retrieved from https://www.naeyc.org/resources/topics/play/toys

NPD Group. (2018). Toy sales globally and in the U.S. both grow by 1 percent in 2017, reports the NPD Group. Retrieved from https://www.npd.com/wps/portal/npd/us/news/press-releases/2018/toy-salesglobally-and-in-the-us-both-grow-by-1-percent-in-2017-reports-the-npd-group/

Parmar, P., Harkness, S., \& Super, C. M. (2004). Asian and Euro-American parents' ethnotheories of play and learning: Effects on preschool children's home routines and school behaviour. International Journal of Behavioral Development, 28, 97-104. doi:10.1080/01650250344000307

Roopnarine, J. L. (2010). Cultural variations in beliefs about play, parent-child play, and children's play: Meaning for child development. In P. Nathan \& A. Peligrini (Eds.), The Oxford handbook of the development of play (pp. 19-37). New York, NY: Oxford University Press.

Rubin, K. H. (1977). The social and cognitive value of preschool toys and activities. Behavioral Science, 9(4), 382-385. doi:10.1037/h0081643

Sandberg, A., \& Samuelsson, I. P. (2003). Preschool teachers' play experiences then and now. Early Childhood Research \& Practice, 5(1). Retrieved from http://ecrp.uiuc.edu/v5n1/sandberg.html

Schweinhart, L. J., Montie, J., Xiang, Z., Barnett, W. S., Belfield. C. R., \& Nores, M. (2005). Lifetime effects: The High/Scope Perry Preschool study through age 40. Ypsilanti, MI: High/Scope Press.

Sherwood, S. A., \& Reifel, S. (2010). The multiple meanings of play: Exploring preservice teachers' beliefs about a central element of early childhood education. Journal of Early Childhood Teacher Education, 31, 322-343. doi:10.1080/10901027.2010.524065

Singer, D., Singer, J., DiAgostino, H., \& DeLong, R. (2009). Children's pastimes and play in sixteen nations: Is free play declining? American Journal of Play, 1, 283-312. Retrieved from http://www.journalofplay.org/sites/www.journalofplay.org/files/pdf-articles/1-3-article-childrens-pastimes-play-in-sixteen-nations.pdf

Soundy, C. S. (2009). Young children's imaginative play: Is it valued in Montessori classrooms? Early Childhood Education Journal, 36, 381-383. doi:10.1007/s10643-008-0282-z

Taggart, J., Heise, M. J., \& Lillard, A. S. (2018). The real thing: Preschoolers prefer actual activities to pretend ones. Developmental Science, 21(3), e12582. https://doi.org/10.1111/desc.12582 